\title{
O ENSINO DE HISTÓRIA PRESENTE NOS \\ PARÂMETROS CURRICULARES DO ENSINO \\ MÉDIO (PCNEM): \\ A CONSTRUÇÃO DO SUJEITO ADEQUADO
}

\section{Marco Antonio Neves Soares*}

RESUMO:

Este texto busca compreender o desenvolvimento da disciplina histórica, para localizar as fundamentações desta, presentes nos Parâmetros Curriculares Nacionais do Ensino Médio (PCNEM).

Neste sentido, recupera a história do ensino de história, assim como as idéias presentes na reforma de ensino, ora em curso. PALAVRAS-CHAVE:

Ensino de História, Parâmetros Curriculares Nacionais do Ensino Médio; Política Educacional

Durante o Império, a disciplina histórica integrava o elenco da dogmática católica, estando inserida em um amplo leque que era o ensino religioso. A História Sagrada era ministrada por clérigos e preceptores, e atendia aos ditames do Padroado Régio: destacar e exaltar a fé e a moral católicas. Nem mesmo as posições laicas da Constituição de 1824 puseram fim à essa subordinação da história à moral religiosa.

Com a criação do colégio D. Pedro II (1837), e mesmo após a sua reforma pedagógica (1853-57), manteve-se a idéia de ensino de história como ensino religioso, devido à influência da Lei Falloux (1850), responsável pela volta da interferência

* Doutor em História, professor do Departamento de História da Universidade Estadual de Londrina - UEL. 
religiosa nas decisões educacionais francesas (BITTENCOURT, 1992-93, p.196-7), buscando eliminar o perigo das doutrinas sociais e do liberalismo.

Este caráter reacionário importado da França fincou raízes, e com o nascimento da república, a disciplina histórica ficou entre duas posições antagônicas. De um lado os defensores da história como apêndice da história sagrada, e de outro os defensores de um ensino humanístico, que estavam divididos em dois grupos, os humanistas clássicos, que compreendiam a história como apêndice e substrato do Latim, da Literatura e da Retórica; e os humanistas liberais, que defendiam um alargamento do campo das humanidades em diferentes disciplinas, como filosofia, história, geografia, línguas modernas.

A construção de um sentimento nacionalista, que passou a ser reforçado no fim do século XIX com a instauração do regime republicano, aliada à concepção de História como mestra da vida, foi responsável pela criação de personagens históricos que deveriam. servir de modelo à cidadania e que deveriam ser reconhecidos como símbolos fundadores da nacionalidade.

Elencada no rol das "humanidades", a história serviu de instrumento e estratégia para a formação de um imaginário que tentava fundamentar a noção de pátria. Segundo Ortiz (1983) ela foi utilizada para a construção da identidade nacional, fundamentando-se em idéias racistas que permeavam o positivismo. Servia, portanto, para a formulação do conceito de identidade, pois estabelecia uma memória coletiva com a construção dos heróis, para a glorificação do Estado Nacional (CARVALHO, 1990).

Essas idéias ecoaram em Tobias Barreto, Silvio Romero, Euclides da Cunha, Capistrano de Abreu, entre outros, ávidos por criarem os elementos que sustentariam esta nova sociedade, sob os auspícios da ordem e do progresso. Neste sentido, a 
república, desde o início, tratou de cuidar da constituição da galeria dos heróis nacionais, pela instituição tanto dos feriados e festas cívicas quanto pela seleção dos personagens a serem cultuados (NADAI, 1992-93, p.151).

Sob esta ótica, o conceito de fato histórico, a neutralidade e a objetividade do historiador/professor, procuravam reivindicar a cientificidade da história, e ela impunha uma identificação com o passado de maneira linear e evolutiva. Segundo Elza Nadai, essa forma de ensino, determinada desde sua origem como disciplina escolar, foi o espaço da história oficial na qual os únicos agentes visíveis do movimento social eram o Estado e as elites (1992-93, p. 152)

A periodização empregada obedeceu a uma cronologia política, marcada pelos acontecimentos vultuosos, ou pela ação dos grandes homens, ou ainda pelos acontecimentos diplomáticos. Elza Nadai bem compreendeu essas características ao afirmar que essa visão de história era monolítica, operando somente com as regularidades e sucessões, fazendo do ensino da história o veículo de imposição de um único agente, o indivíduo.

A mudança dessa visão conservadora e reacionária de história e de ensino de história ocorreu somente com a Revolução de 1930 e o seu projeto modernizador. As primeiras medidas concretas para a inovação do ensino em pauta, ocorreu com a criação da USP e da Faculdade de Filosofia, Ciências e Letras em 1934, e depois com a fundação da Universidade do Brasil no Rio de Janeiro. Vamos ter, paralelo a esse processo, a especialização e especificação do ofício do historiador. $\mathrm{O}$ auto-didatismo foi abandonado em nome de uma formação acadêmica e moderna, executada por professores estrangeiros como Fernand Braudel, Claude Lévy-Strauss, Roger Bastide, entre outros. Nesta renovação, temos ainda que ressaltar os papéis de Sérgio Buarque de Holanda, Caio Prado Jr. e Gilberto Freyre, que devido à 
penetração do pensamento marxista, sobretudo nos dois primeiros, possibilitou o surgimento da articulação entre a história e o social, a partir da noção de luta de classes.

No caso da FFCL, os estudos históricos digladiavam-se em torno de três tendências: a dos historiadores franceses, em torno da cadeira de História das Civilizações; a dos membros do Instituto Histórico e Geográfico, efetivados na cadeira de História do Brasil, de caráter conservador e uma terceira força, hoje esquecida, representada por Paul V. Shaw, de tendência serial-interdisciplinar.

Essas três vertentes acabaram propiciando um conjunto de experiências heterodoxas, mas delas sairá a história crítica, muitas vezes confundida com a marxista a que mais eco encontrou na academia. Esta hegemonia manteve-se na Universidade, mesmo após o golpe 1964, enfraquecendo-se somente no reboque da experiência socialista.

Nas décadas de 50-60, a renovação foi direcionada para o aprofundamento dos fundamentos científicos, chegando até a escola secundária, devido ao desenvolvimento da profissão de historiador e dos licenciados em história. O surgimento desse profissional, agora especializado em seu ofício, propiciou uma melhoria de qualidade do ensino de história. Assim, privilegiouse o social, sendo necessário o uso do marxismo para a obtenção das ferramentas, possibilitando a compreensão da realidade e das desigualdades.

Mas, apesar da superação da simples memorização ou do registro objetivo e pretensamente imparcial, o conteúdo ainda era direcionado para um discurso explicador, unívoco, generalista, totalizador e eurocêntrico. Em busca da identidade nacional, criaram outros mitos como a democracia racial, a cordialidade do brasileiro, nação de uma única língua, dentre outros.

É necessário que compreendamos que essas mudanças da historiografia foram simultâneas a um alargamento do 
alcance da escola secundária no período do pós-guerra. A acelerada urbanização e industrialização exigiam uma universalização da alfabetização, minando as bases do ensino secundário elitista, ao garantir o acesso das classes urbanas.

Buscou-se então uma experimentação no ensino, com o aparecimento de diversos métodos, currículos, conteúdos, práticas, para colocar o ensino de história no passo de seu tempo. No entanto a ditadura veio a acabar essa experiência que se proliferava pelo Brasil.

No governo militar, a escola e a Universidade distanciaramse: a Universidade resistia às cassações, censuras, admoestações, e delas sobrevivia o marxismo como o escopo dos estudos históricos. A escola pública, para atender ao projeto desenvolvimentista, popularizava-se, abrindo curso noturnos, e encerrando com os exames de admissão ao então chamado segundo grau.

Neste contexto, surgiram os cursos de "curta duração", de caráter polivalente e sem fundamentação. $\mathrm{Na}$ escola, foi negada à história, assim como à geografia, a sua especificidade, com a criação do curso de Estudos Sociais. Paralelo à esta disciplina era ministrada a EMC (Educação Moral e Cívica), com suas noções ufanistas de civismo, que servia como controle ideológica das massas e mesmo da burguesia. Mantidas no segundo grau, história e geografia conviviam com OSPB (Organização Social e Política do Brasil), que fazia propaganda dos governos militares, sobretudo o milagre econômico e o despertar do "Gigante Adormecido".

Selva Fonseca compreendeu bem esse processo ao afirmar que

nas mudanças educacionais implementadas após 1964, o ensino de História tornava-se um alvo importante do poder político autoritário dominante, e neste sentido várias medidas governamentais são adotadas, visando o seu enquadramento no binômio do regime: desenvolvimento econômico/segurança nacional (1993, p.13). 
A separaçắo universidade/escola pública transformou o ensino de história em uma prática sem rigor nem fundamento: voltaram os tópicos que deveriam ser decorados, eliminou-se a reflexão com a instituição dos questionários e dos estudos dirigidos, e ao professor de história restou lecionar Estudos Sociais, EMC, OSPB e organizar os Centros Cívicos, assim como os desfiles comemorativos.

Com a redemocratização na década de 80 , o ensino de história estava sem identidade e cada vez mais via seu status diminuído. Enquanto nas Universidades, ao lado do marxismo, que até o momento mantinha-se hegemônico, com um certo atraso chegavam as experiências dos herdeiros da Escola dos Annales, aquilo que ficou conhecido como História Nova. Nas escolas públicas a disciplina continuava sendo desprivilegiada, tendo a sua carga horária paulatinamente reduzida.

Quando as idéias francesas finalmente chegaram à escola, encontraram o ensino de história centrado em visões tradicionais e positivistas desta disciplina, e a reformulação do ensino de história ficou impossibilitada pelas disputas teóricas entre os três vieses, que se digladiavam na CENP-SP, Coordenadoria de Estudos e Normas Pedagógicas, da Secretaria de Educação do Estado de São Paulo, inviabilizando qualquer normatização das propostas curriculares para o ensino de história.

Aparentemente as tendências marxistas sagraram-se vencedoras quando no fim da década de 80 e início da de 90, a SEE-SP adotou a visão da história dividida em eixos temáticos, privilegiando o mundo do trabalho e das outras relações econômicas. Nessa proposta, os eixos articulariamse anacronicamente, cabendo ao professor sistematizar aquelas informações.

Apesar de algum sucesso nas chamadas Escolas-Padrão, esta reforma sucumbiu à má formação dos professores e às suas 
péssimas condições salariais, que inviabilizaram a aquisição de livros, assim como a assinatura de jornais e revistas, além da sua informatização. Para resolver a questão salarial, o governo criou duas carreiras de magistério: aquela que ministrava aulas em escolas comuns, e aqueles que o faziam nas Escolas-Padrão, recebendo treinamento e gratificações salariais. No bojo das disputas políticas no estado, essas experiências foram abandonadas, deixando um vazio metodológico no ensino de história.

Com a crise do marxismo, as tendências ligadas à História Nova tornaram-se, por sua vez, hegemônicas. Redimensionando o objeto da história, ampliando a noção de documento e multiplicando a abordagem, a tendência francesa fez a Universidade pensar o cotidiano, historicizar os hábitos, ocuparse de mitos, reaproximar-se enfim de uma história mais humana, onde o econômico deixava de ser o motor, para colocar em seu lugar, múltiplas determinações.

O distanciamento entre os cursos universitários de história e a disciplina escolar se acentuava ainda mais. O governo federal, através das Secretarias de Ensino Fundamental e de Ensino Médio e Tecnologias, no afã de impor o modelo educacional ditado pela globalização, tratou de estabelecer um currículo fundamentado na complementação entre humanidades, ciências naturais e tecnologia, em busca de uma síntese.

Para atingir esse objetivo, em 1996 foi aprovada a LDB, que em seu artigo $2^{\circ}$. destacava a finalidade da educação: o preparo para o exercício da cidadania, e qualificação para o trabalho. A mesma LDB, em seu artigo 35, ao especificar os objetivos do Ensino Médio, afirma que eles visam a consolidação e o aprofundamento dos conhecimentos, ao mesmo tempo que prepara o aluno para o trabalho e para a cidadania, baseado em orientações éticas, além de possibilitar a compreensão dos fundamentos científicos e tecnológicos de nosso tempo. 
O ensino da história, visando tais objetivos, passou a operar com a interdisciplinaridade, transversalidade e o chamado currículo por competências, ou seja, no parâmetro do ensino de história buscou-se um ecletismo onde marxismo, tradições francesa e inglesa, associaram-se às idéias da ciência política e do direito, na tentativa de criar os espaços para o desenvolvimento da cidadania e para a capacitação para os usos das tecnologias.

Na visão dos Parâmetros Curriculares Nacionais, o ensino de história deve articular-se com as outras disciplinas que integram a área denominada Ciências Humanas e suas Tecnologias, objetivando:

sedimentar e aprofundar temas estudados no Ensino Fundamental, redimensionando aspectos da vida em sociedade e o papel do indivíduo nas transformações do processo histórico, completando a compreensão das relações entre a liberdade (ação do indivíduo que é sujeito da história) e a necessidade (ações determinadas pela sociedade que é produto de uma história) ${ }^{1}$.

Neste sentido, o ensino de história e a sua área fazem parte de uma estratégia maior, que trata de absorver a crescente demanda pelo Ensino Médio, modernizá-la, ou seja, capacitála para o uso de diferentes tecnologias, com o intuito de transformá-la em um exército de reserva pronto para assumir postos de trabalho mais qualificados, substituindo desta maneira, a mão-de-obra desqualificada.

Esta estratégia, segue a lógica de nossa sociedade pósindustrial, onde os custos da produção caem na medida em que ela se sofistica tecnologicamente, provocando um outro

${ }^{1}$ BRASIL, Ministério da Educação, Secretaria de Educação Média e tecnológica. Parâmetros Curriculares Nacionais: Ensino Médio. Brasília: Ministério da Educação, 1999. 
ônus, que é social, pois se a sociedade se enriquece com a nova revolução industrial, conseqüentemente ela deve arcar com os custos do incremento do desemprego estrutural derivado desta revolução (SCHAFF, 1990, p. 35).

A nossa contemporaneidade também orienta-se pela pulverização das tradições, pelo mito do consumo, pela visão positivista do desenvolvimento tecnológico, pela instantaneidade das informações e pela limitação do desenvolvimento do indivíduo e da vida social. Os PCNEM conseguiram enxergar esta volatilidade que caracteriza nosso tempo, mas não puderam propor algo mais sólido do que uma também mítica síntese entre tecnologia e desenvolvimento humano.

Trata-se da proposição de um novo humanismo, que deveria guiar as relações entre o homem, o saber e as tecnologias no século XXI. Este humanismo seria justificado pela História, pela Antropologia, pela Filosofia e pela Economia, pois tais disciplinas desenvolvem tecnologias ligadas ao planejamento, gestão e controle de informações e essas tecnologias, e não só aquelas diretamente envolvidas com o manuseio de máquinas e ferramentas, têm sido responsáveis por transformações radicais nos processos produtivos ${ }^{2}$.

A síntese entre humanismo e tecnologia é justamente o fundamento onde se estrutura a proposta curricular, na busca de superar os paradigmas ditados pela tradição positivista. Busca ao mesmo tempo a superação das doutrinas humanistas clássicas sustentado na inexorabilidade do desenvolvimento

\footnotetext{
${ }^{2}$ O sentido do aprendizado na área. In: Brasil, Ministério da Educação, Secretaria de Educação Média e tecnológica, Parâmetros Curriculares Nacionais: Ensino Médio. Brasília: Min. Da Educação, 1999, p. 284. Na área de Ciências Humanas e suas Tecnologias, os PCNEM reivindicam o desenvolvimento de uma tecnologia fundamentada nas Ciências Humanas, estando tais tecnologias ligadas ao trato da informação: sua produção, veiculação, gestão e triagem.
}

História \& Ensino, Londrina, v. 8, p. 29-44, out. 2002 
tecnológico, e a compreensão do impacto deste desenvolvimento sobre o indivíduo e sobre a sociedade, já que ela reivindica a reflexão sobre a relação homem/tecnologia.

Para atingir este objetivo, os Parâmetros afirmam que as diferentes áreas do conhecimento deveriam orientar-se pelo estabelecimento de competências a serem desenvolvidas pelos alunos. Estas competências são compreendidas como esquemas mentais, e deduzidas dos pensamentos de Jean Piaget e Noam Chomsky, e implicam em ações e operações mentais de caráter cognitivo, sócio-afetivo ou psicomotor que mobilizadas e associadas a saberes teóricos ou experienciais geram habilidades, ou seja, um saber fazer (BERGER FILHO, 1998).

Neste sentido, seriam nove as competências que a área de Ciências Humanas deveria desenvolver, indo do reconhecimento da individualidade à apropriação do uso dos desenvolvimentos tecnológicos. Este movimento implicaria necessariamente no trato da tecnologia como uma extensão das capacidades humanas, com vistas à sua otimização. Para isto, os diferentes recursos tecnológicos deveriam estar inseridos no cotidiano dos indivíduos e/ou grupos sociais para a promoção da igualdade de condições, pois esta garantiria o respeito às diferenças inerentes ao conjunto social (sexo, cor, religião), afastando com isso os temores de uma sociedade tecnológica a serviço da exploração e alienação do homem³ .

É evidente que para o cumprimento destes parâmetros, a disciplina histórica passa a ser um instrumento ideológico importante na construção dos valores objetivos como ser histórico e cidadania social, porém eivados de valores neoliberais, reivindicados como universais para a educação no

${ }^{3}$ Competências e habilidades. In: Brasil, Ministério da Educação, Secretaria de Educação Média e tecnológica. Parâmetros Curriculares Nacionais: Ensino Médio. Brasília: Min. Da Educação, 1999, p. 296 
século XXI. Esta, segundo a orientação do MEC, deveria pautar-se em quatro princípios: aprender a conhecer, a fazer, a conviver e a ser, onde o primeiro, considerado base de toda educação, sustentaria os demais. Assim estaria garantida a educação, quando se dá apropriação e transposição de conhecimentos para novas situações é que se pode dizer que houve aprendizado ${ }^{4}$.

Este hic et nunc neo-liberal exige que a disciplina histórica parta de questões colocadas pelo presente para posterior investigação acerca delas em outros tempos, sendo percebidas no eixo das mudanças e das continuidades. Para que o processo se instaure, é necessário que a história dialogue com as demais disciplinas, inclusive as de extra-áreas, a fim de consolidar e aprofundar o que já foi estudado no Ensino Fundamental.

A história, assim como as demais disciplinas, deveriam, em conjunto, formar uma cultura educacional, que permitisse a compreensão das transformações e a percepção da velocidade destas, pelos adolescentes. Pensando o presente, eles elaborariam estratégias para sua inserção no mundo do trabalho e no da autonomia, compreendidos como escolhas a serem feitas ante o mercado.

A abordagem que perpassa os Parâmetros para o ensino de história indica claramente que a escola deverá se render aos temas da História Nova, sobretudo aqueles ligados ao cotidiano, elaborando as articulações entre a micro e a macrohistória, buscando nas singularidades dos acontecimentos as generalizações necessárias para a compreensão do processo histórico ${ }^{5}$.Dentro deste arcabouço teórico-metodológico, a

${ }^{4}$ Idem , p. 289

${ }^{5}$ Conhecimentos de História. In: Brasil, Ministério da Educação, Secretaria de Educação Média e tecnológica. Parâmetros Curriculares Nacionais: Ensino Médio. Brasília: Ministério da Educação, 1999, p.300. 
interdisciplinaridade é necessária, constituindo um instrumental maior para a percepção do tempo presente, do mundo social e de suas representações. As diferentes metodologias relativizaram a noção de documento e a proposta de ensino de história endossou a tese de Michel de Certeau (1988) de que ele é construído durante o fazer histórico.

Para atingir essa sofisticação, tem que aceitar a maximização do ensino da língua portuguesa, assim como a otimização do ensino das artes e da filosofia para desenvolver as competências da leitura e da interpretação de textos, capacitando os indivíduos à compreensão do universo caótico de informações e deformações que se processam no cotidiano ${ }^{6}$.

Observando esses princípios, os alunos do Ensino Médio ao terem aulas de história, estabeleceriam leituras acerca de seu tempo histórico, utilizando os conhecimentos já adquiridos no Ensino Fundamental, que problematizados, permitiriam reconhecer os diferentes tempos (mítico, escatológico, cíclico, cronológico) como representações das temporalidades naturais.

Observando o tempo histórico, poderiam localizar quando as temporalidades não-naturais foram se constituindo e se estabelecendo. Assim teríamos a experiência da duração, que por sua vez permitiria pensar as revoluções como o momento de ruptura, mudança, alteração. Estas abstrações, objetivadas permitiriam que o aluno aprenda, de forma dialética, as relações entre presente-passado-presente, necessárias à compreensão das problemáticas contemporâneas, e entre presente-passado-futuro, que permitem criar projeções e utopias?

O humanismo, neste momento, é novamente reivindicado, desta vez para justificar que as noções do tempo partem das relações

\footnotetext{
${ }^{6}$ Idem, p. 301.

${ }^{7}$ Idem, p.303.
} 
entre homem e natureza. Apoiando-se em Levi Strauss reconhece que o tempo da natureza foi paulatinamente substituído pelo tempo da fábrica. Sustentando-se em Fernand Braudel, reafirma diferentes temporalidades, breves, conjunturais e estruturais. Tais fundamentações são importantes pois é a partir delas que ocorreria a apreensão do tempo histórico, e esta apreensão pode favorecer a formação do estudante como cidadão, aprendendo a discernir os limites e possibilidades de sua atuação, na permanência ou na transformação da realidade histórica em que vive ${ }^{8}$.

Os PCNEM também trazem as contribuições de Fernand Braudel e de Jacques le Goff, acerca da cultura material como veículo da memória, e sob tais leituras sugere a utilização do Patrimônio Cultural como fonte para os estudos históricos no Ensino Médio. Trata-se da valorização do patrimônio, para que este seja um dos indicadores das transformações e/ou das permanências pelas quais a sociedade se deixa revelar, uma abordagem necessária a ser realizada com os educandos, situandoos nos "lugares da memória" construídos pela sociedade e pelos poderes constituídos, que estabelecem o que deve ser preservado e relembrado e o que deve ser silenciado e "esquecido".

Partindo dos problemas contemporâneos, cabe ao professor selecionar as competências que deve desenvolver, para poder elaborar os conteúdos que sejam significativos ao adolescente. Tal seleção implica, necessariamente, em tomadas de posições teórico-metodológicas claras e objetivas, para que a constituição dos objetos sejam os melhores para a compreensão da contemporaneidade.

A concepção de história, presente nos PCNEM, é de caráter pragmático, buscando primordialmente a atender o mercado, provendo-lhe com mão-de-obra qualificada, com

$\begin{array}{ll}8 & \text { Idem, p. } 304 . \\ 9 & \text { Idem, p. } 306\end{array}$

História \& Ensino, Londrina, v. 8, p. 29-44, out. 2002 
cidadãos críticos de seu papel histórico e com indivíduos cientes das ações pautadas pela ética e pela justiça, buscando amalgamar o conceito de humanidade e de cidadania à potencialidade produtiva da pessoa (ARIAS NETO, 1999, p.109), e não no desenvolvimento pessoal, enquanto cidadão responsável pelas transformações sociais. Ou seja, nega o princípio aristotélico do homem político, pois lhe tolhe as decisões sobre o estado, que passa a ser um ente que existe para servir os ditames da produção capitalista.

Longe de possibilitar a emergência do ser humano livre, participativo e transformador, que faz da máquina uma extensão de si, os PCNEM reivindicam a construção de um sujeito adaptável às mudanças periódicas da atual fase do capitalismo. Neste sentido, o pragmatismo presente nos Parâmetros engendra um homem reificado, que tem sua existência limitada pela sua capacidade de moldar-se para servir os interesses do capital.

Hans-Georg Gadamer já apontara que em uma civilização técnica, é inevitável que se não se premie tanto a potência criadora do indivíduo, como seu poder de adaptação (1983, p. 45), por isso a ênfase no treinamento, na organização, na gestão, e não na produção de objetividades. Desta maneira, a formulação presente neste parâmetro para o ensino de história, age cumprindo o que foi chamado de coerência imanente entre construção metódica e de fabricação técnica (GADAMER, 1983, p. 42), que se pauta em dois princípios, a saber, o primeiro, onde o artificial sobrepõe-se ao natural estabelecendo uma necessidade de consumo; e o outro que exige que o humano não se objetive mais no mundo, pois a necessidade criada limita a liberdade.

Sabemos que homens livres são inadequados ao mercado, porque críticos e criativos, são incapazes de viver sob os influxos da repetição ditada pelo mundo globalizado. Homens livres 
são capazes de incessantemente engendrar aquilo que Milton Santos chamou de nova consciência de ser mundo. Por isso é imperativo que a produção do conhecimento, que comportase como extensão da técnica atualmente utilizada para construir um mundo confuso e perverso, passe a ser uma condição da construção de um mundo mais humano. Basta que se completem as duas mutações ora em gestação: a mutação tecnológica e a mutação filosófica a espécie humana (SANTOS, 2000, p. 174).

\section{Referências Bibliográficas}

ARIASNETO, José Miguel. Entre o nada e o anódino: parâmetros, diretrizes e a reforma da educação nacional. História e Ensino, v. 5, 1999, p.103-126 BERGER FILHO, Ruy Leite. Formação baseada em competências. In: CONGRESSO DE EDUCAÇÃO TECNOLÓGICA DOS PAÍSES DO MERCOSUL, 5., 1998, Pelotas. Anais... Pelotas: MEC/SEMTEC/ETFPEL, 1998.

BITTENCOURT, Circe. Os confrontos de uma disciplina escolar: da história sagrada à história profana. Revista Brasileira de História, v. 13, set.92/ago.93, p. 193-221.

BRASIL, Ministério da Educação. Secretaria de Educação Média e tecnológica. Parâmetros Curriculares Nacionais: Ensino Médio. Brasília: Ministério da Educação, 1999.

CARVALHO, José Murilo. A formação das almas. SP: Cia. das Letras, 1990.

FONSECA, Selva. Caminhos da História Ensinada. Campinas: Papirus, 1993.

GADAMER, Hans-Georg. A Razão na Época da Ciência. Rio de Janeiro: Tempo Brasileiro, 1983.

NADAI, Elza. O ensino de História no Brasil: trajetórias e perspectivas. Revista Brasileira de História, v. 13, set.92/ago.93, p.143-162. 
ORTIZ, Renato. Cultura Brasileira e Identidade Nacional. São Paulo: Brasiliense, 1985.

SANTOS, Milton. Por uma Outra Globalização: do pensamento único à consciência universal. Rio de Janeiro: Record, 2000.

SCHAFF, Adam. A Sociedade Informática. São Paulo: Brasiliense, 1990.

\section{ABSTRACT:}

This paper intends to comprise the developement of the historical discipline for seek its fundamentations into Brazil Medium Teaching Curriculars Parameters. In this meaning, it recoveries the history teaching history, as well as the ideas presents in the teaching reformation in progress.

KEY-WORDS:

History Teaching, Brazil Medium Teaching Curriculars Parameters, Educational Policy 